\title{
Effect of Recharge and Irrigation on the Variation of Nitrate in the Groundwater of Wadi Djendjen (Jijel-North-East Algeria)
}

\author{
Abdelmadjid Boufekane ${ }^{1}$, Omar Saighi ${ }^{2}$ \\ ${ }^{1}$ Water and Environmental Engineering Laboratory, Higher National School of Hydraulics, Blida, Algeria \\ ${ }^{2}$ Department of Geology, Faculty of Earth Sciences and Country Planning, \\ University of Sciences and Technology Houari Boumediene, Algiers, Algeria \\ Email: boufekane_ab@yahoo.fr, osaighi@hotmail.com
}

Received July 26, 2013; revised August 27, 2013; accepted September 28, 2013

Copyright (C) 2013 Abdelmadjid Boufekane, Omar Saighi. This is an open access article distributed under the Creative Commons Attribution License, which permits unrestricted use, distribution, and reproduction in any medium, provided the original work is properly cited.

\begin{abstract}
This paper presents the effect of recharge and irrigation on the variation of nitrate in the groundwater of wadi Djendjen (Jijel-North-East Algeria) where the intensive use of fertilizers and the recycling of irrigation water have resulted in an alarming increase in nitrate concentrations. In this plain, the groundwater is increasingly polluted by excessive use of fertilizers in agriculture. Indeed, in several areas of irrigated vegetable crops, water contains nitrate levels which exceed the allowed standards for human consumption. The present study consists of a spatio-temporal monitoring of nitrate in groundwater in relation to the dilution caused when charging during the rainy season, on the one hand, and to the leaching by irrigation water during the dry season, on the other hand. The results obtained show an increase in the contamination of groundwater by nitrates and their seasonal variations under the effects of recharge and irrigation.
\end{abstract}

Keywords: Agricultural Pollution; Nitrates; Recharge; Irrigation; Groundwater

\section{Introduction}

The agricultural pollution is a major cause of the deterioration of groundwater quality [1]. Agricultural activities are probably the most significant anthropogenic sources of nitrate contamination in groundwater (Carey and Lloyd, 1985; De Simone and Howes, 1998) [2,3]. The development of agricultural land and the requirements of a good production require an input of fertilizers which often leads to groundwater pollution by nitrates due to their high solubility and their weak affinity for ionic exchanges (Macko and Ostrom, 1994; Stumm and Morgan, 1996) [4,5].

Many studies proved that husbandries are the probable cause of the excessive nitrate levels in the groundwater (Lake et al., 2003; Mitchel et al., 2003; Carey, 2002) [6]. Concentrations raised out of nitrates in drinking water are related to health issues such as the methemoglobinemy for children and the cancer of the stomach for adults (Wolfe and Patz, 2002; Hall et al., 2001) [7,8]. There exist values of limiting acceptable nitrate concentration in drinking water. WHO to define an obligatory limiting value fixed at $50 \mathrm{mg} / \mathrm{l}$ [9].
Thus, in the plain of the wadi Djendjen, the increase in the contents of nitrates of the groundwater found in certain zones, is related to surpluses of manures brought to the cultures. To address this question, a monthly sampling of groundwater for chemical analysis was carried out during 3 consecutive years in four wells distributed in terms of the use of land, the use of fertilizer and the frequency of irrigation.

\section{Presentation of the Study Area}

The area of the study is located in the north-east of Algeria. The alluvial aquifer of this area forms part of the coastal plains region of Jijel (Figure 1); it covers an area of $58 \mathrm{~km}^{2}$ and opens to the north of the Mediterranean Sea. It corresponds to the lower part of wadi Djendjen and its tributaries which contribute to the groundwater recharge.

The maritime location of this plain gives it a mild and damp climate. Between the winter and summer, the monthly median values of temperatures vary from 11 with $25^{\circ} \mathrm{C}$ (the average air temperature is $17^{\circ} \mathrm{C} /$ year), the humidity relative from $70 \%$ to $75 \%$ and the evaporation 


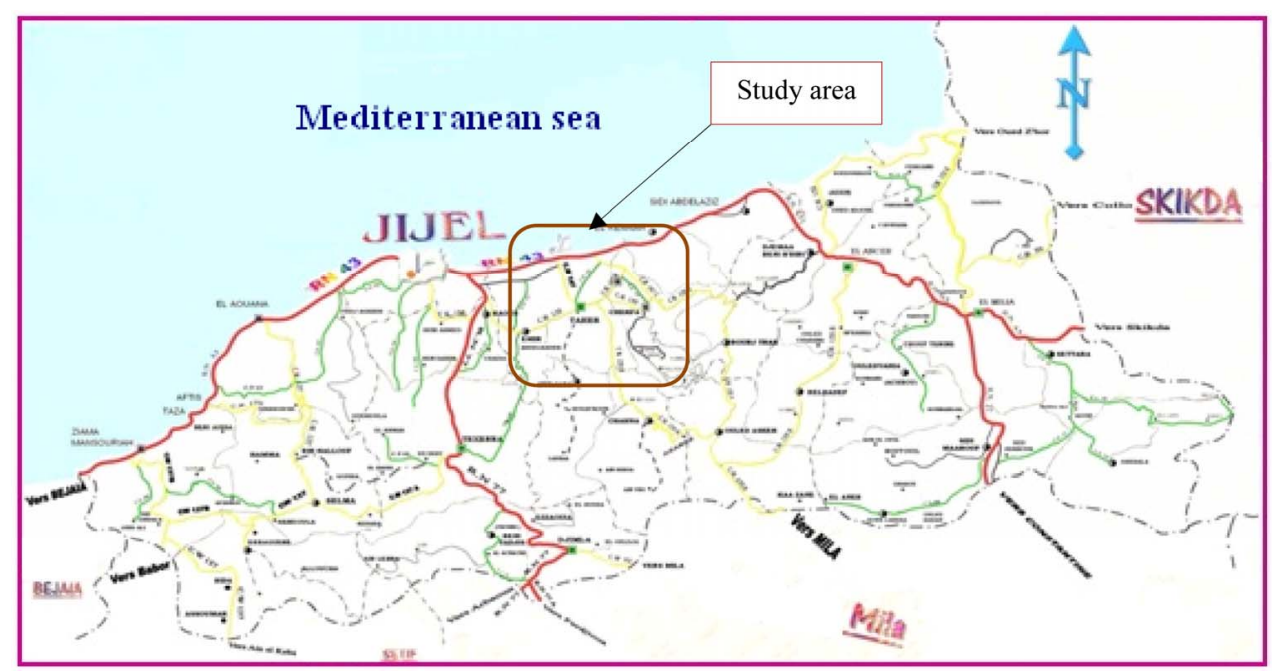

Figure 1. Location map of the study area.

from 41 to $80 \mathrm{~mm}$. The rainfall, relatively high, reaches $900 \mathrm{~mm} /$ year [10].

The geological substratum of the area consists of gneiss and the schist. However, the parts of swallow, sedimentary formations mainly marly Miocene age and Pliocene cover these metamorphic facies. Finally, the depressions and valleys (Figure 2) are filled with quaternary alluvial deposits which are interesting terraces aquifers. The thickness of the aquiferous formation increases from upstream to downstream $(30 \mathrm{~m}$ in Taher Ouassef and $100 \mathrm{~m}$ in Tassoust).

The groundwater recharge is mainly directed by infiltration of rainfall and the low water situation by the wadi Djendjen (Figure 3). The aquifer forms part of the socio-economic development of the region by the exploitation of the domestic wells and boreholes (10 million $\mathrm{m}^{3} /$ year).

\section{Materials and Methods}

The study is based on a monthly piezometric monitoring of groundwater and on nitrates analyses carried out on samples of groundwater taken monthly in four water points for 3 consecutive hydrological years (2009 to 2012).

The chemical analyses were performed by the colorimetric method. The technical characteristics of the device photometric are: UV visible-precision $0.10 \mathrm{mg} / \mathrm{l}$; Interval of measurement 0 - $30 \mathrm{mg} / \mathrm{l}$; wavelength $555 \mathrm{Nm}$ and the color yellow amber.

The four sampling points, selected according to land use and anthropic activity are located in the downstream half of the plain where vegetable gardening, with the high demand of water and nitrogen, occupies an important place. As example, the water points 3 and 4 correspond to zones of plasticulture heavily fertilized and ir-

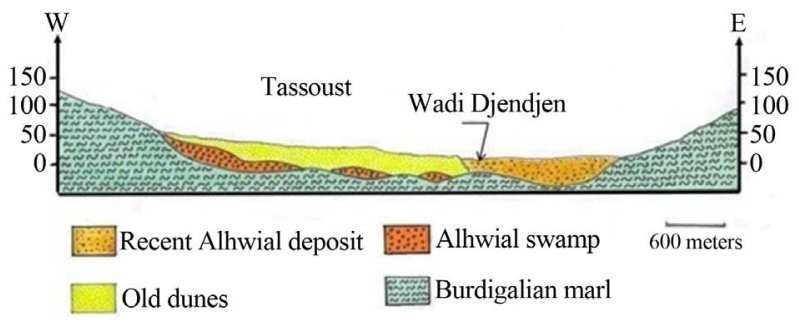

Figure 2. Geological section in the low zone of wadi Djendjen.

rigated. In this part, the water is not very deep (less the 6 meters) and its good permeability does not allow it to enjoy a sufficient natural protection to defend against surface pollution.

From upstream downstream, the characteristics of the water points selected for the study (Figure 4) are as follows:

- Point N1 corresponds to a drilling situated in a field of drinking water abstraction. Neither fertilized nor irrigated, its zone of influence coincides with a perimeter of protection of groundwater.

- Point N2 corresponds to a drilling located in an agricultural zone little or no fertilized, irrigated from aquifer little loaded with nitrates.

- Point N3 corresponds to a drilling situated in a zone of vegetable gardening and greenhouse regularly fertilized; this zone is irrigated from the aquifer.

- Point N4 corresponds to a drilling located in an agricultural zone fertilized and irrigated only for the summer period.

The other data used refer to groundwater piezometric fluctuations and meteorological data recorded at the coastal station of Achouat.

They relate to rainfall, temperature, relative humidity and evaporation. 


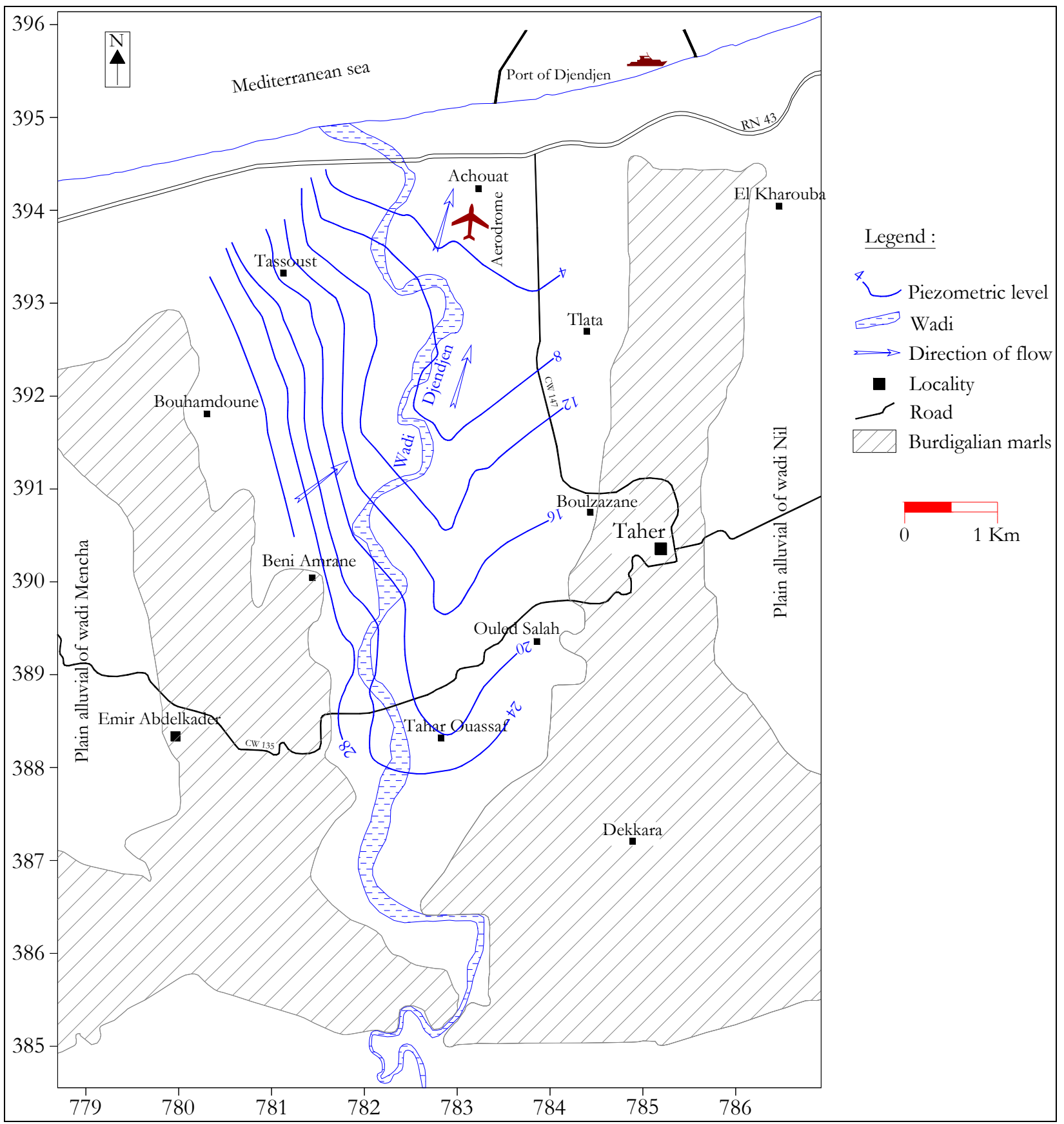

Figure 3. Piezometric map in the plain of wadi Djendjen (May 2012).

\section{Results and Discussions}

The graph (Figure 5) that follows shows that the rainy season takes place in winter, between November and March. It is therefore natural that, on the piezometric level, the groundwater is in situation of "high water" between December and May, with a maximum in MarchApril.

On the scale of the year, the piezometric fluctuations vary from $2.5 \mathrm{~m}$ in point 1 , which is the most downstream, with $3.5 \mathrm{~m}$ in point 4 , upstream.
In terms of nitrate, water collected in points 1 and 2, located in zones not fertilized, sometimes with perimeters of protection, is characterized by low values (less than $27 \mathrm{mg} / \mathrm{l}$ ), while those collected in points 3 and 4, which form part of zones of vegetable gardening fertileized and regularly irrigated, the concentrations are higher (60 to $120 \mathrm{mg} / \mathrm{l}$ ). Aside from point 2 which is in an area irrigated with waters little loaded with nitrate (3 - 11 $\mathrm{mg} / \mathrm{l})$.

Figure 5 shows that the concentration of nitrates in the 


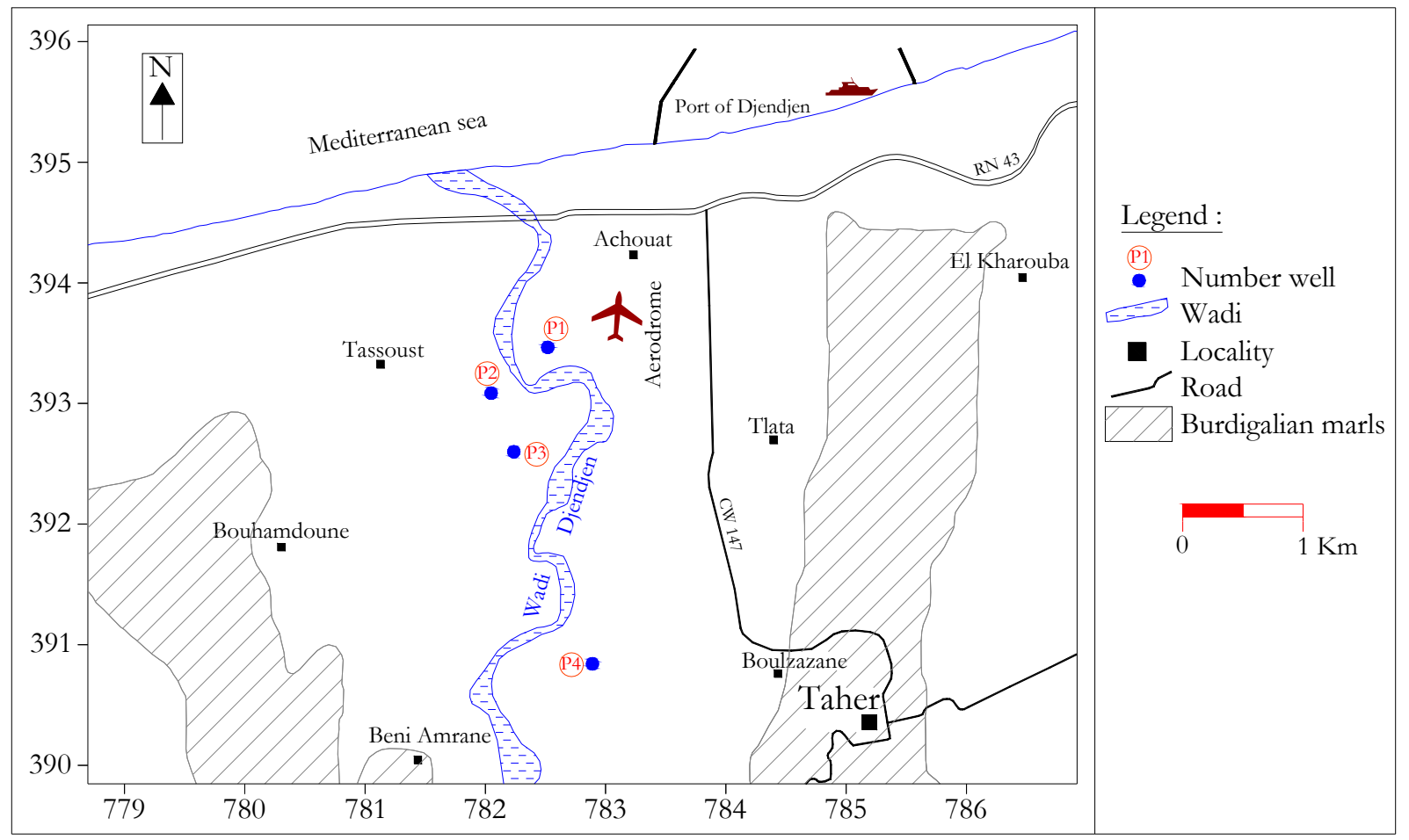

Figure 4. Location of groundwater monitoring well.

aquifer changes inversely with the piezometry. Indeed, they pass from a minimal value when the groundwater is in situation of "high water" to maximum in situation of "low water". This translates the dilution effect caused by recharge during the rainy season. This dilution effect is nevertheless insufficient to bring the nitrate contents to acceptable values, especially where the fertilizer contributions are important, as in point N3.

More explicitly, each water point has its specificity as follows:

- The water point N1 which is a drilling located in a field of drinking water abstraction, reflects a natural state, without fertilizers no irrigation. The nitrate levels in the groundwater (less $27 \mathrm{mg} / \mathrm{l}$ ) are still below the threshold limit for human consumption, in spite of light increase in summer (Figure 5(b)).

- The water point N2 illustrates the characteristic of a zone not fertilized but irrigated with water little loaded with nitrates (3 - $11 \mathrm{mg} / \mathrm{l}$ ). In this case, the low nitrate levels which characterize the groundwater, are stable all the year (Figure 5(c)), oscillating around a value of 5 $\mathrm{mg} / \mathrm{l}$. They undergo an effect of dilution regularly, either by the winter rain, or by water of irrigation little mineralized, in summer.

- The water point N3 corresponds to a zone of intense agricultural practices and greenhouse, with permanent contributions of fertilizer and a frequent irrigation carried out starting from the well N3. The leaching of nitrates and their transfer to the groundwater remains all the year, with an effect accentuated in summer (Figure 5(d)). The nitrate levels are constantly with the top of the acceptable threshold: about $55 \mathrm{mg} / \mathrm{l}$ in winter, in spite of the effect of dilution generated by the rain and higher than 120 $\mathrm{mg} / \mathrm{l}$ in summer, due to leaching and transfer of nitrate to groundwater by irrigation water.

- The fourth point represents an agricultural zone irrigated and fertilized only in summer season. In spite of an intermittency of the fertilizer contributions, the diagram of evolution of the nitrate levels (Figure 5(e)), is similar to the preceding case but with lower values (maximum $70 \mathrm{mg} / \mathrm{l})$. The dilution effect caused by the winter recharge is however more efficient to lower the nitrate concentrations with $25 \mathrm{~m} / \mathrm{l}$.

In addition, the low nitrate levels recorded on the level of the perimeters protected (as at the water $\mathrm{N} 1$ point), testify to the feature not generalized of the nitric contamination. Drainage waters which join the rivers are still healthy. The main source of nitrate excess in groundwater is of agricultural origin. It is specific, since is highlighted only at plots excessively fertilized and irrigated.

Finally, it should be noted that in addition to its low efficiency, the technique of surface irrigation, not in agreement with the economy of water, is largely responsible for the training of nitrate to groundwater. It also helps to maintain the level of water (close enough to the surface), favoring capillary evaporation in summer, increase in hydro-chemical contents and that of nitrates. This is also what is found in 3 out of 4 water points studied. 


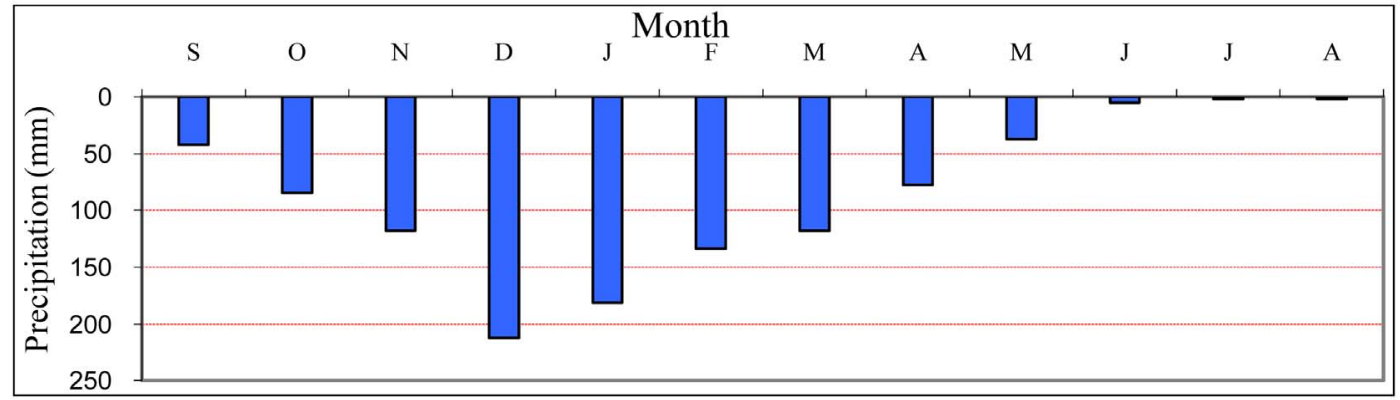

(a)

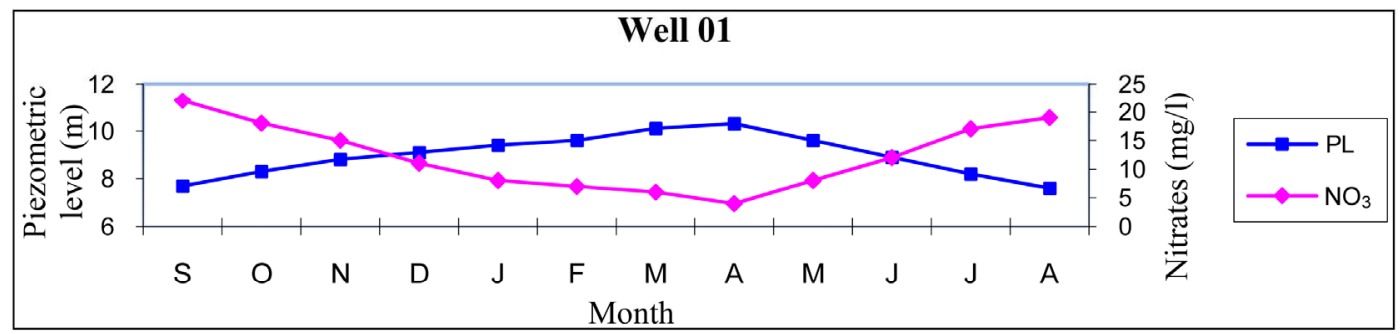

(b)

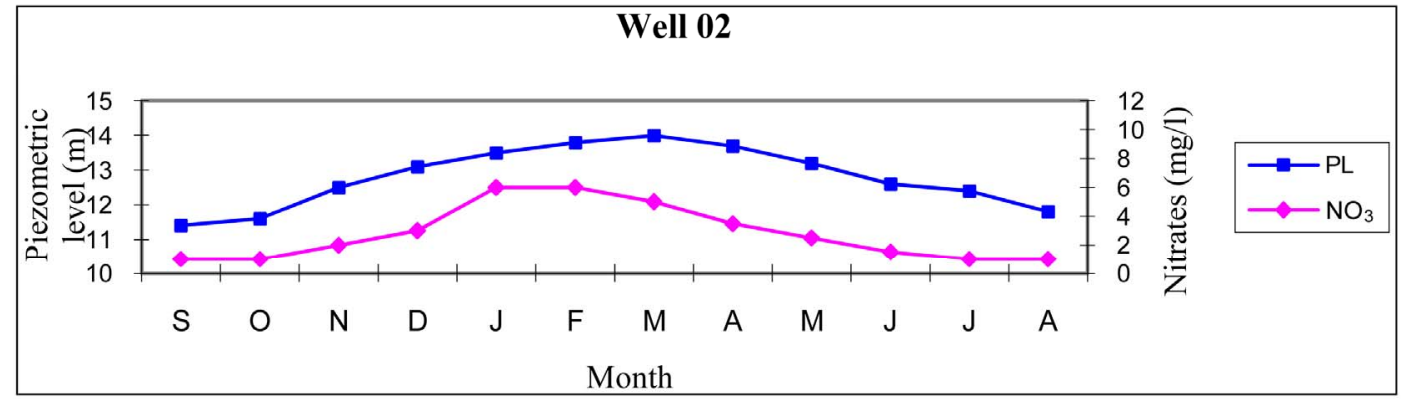

(c)

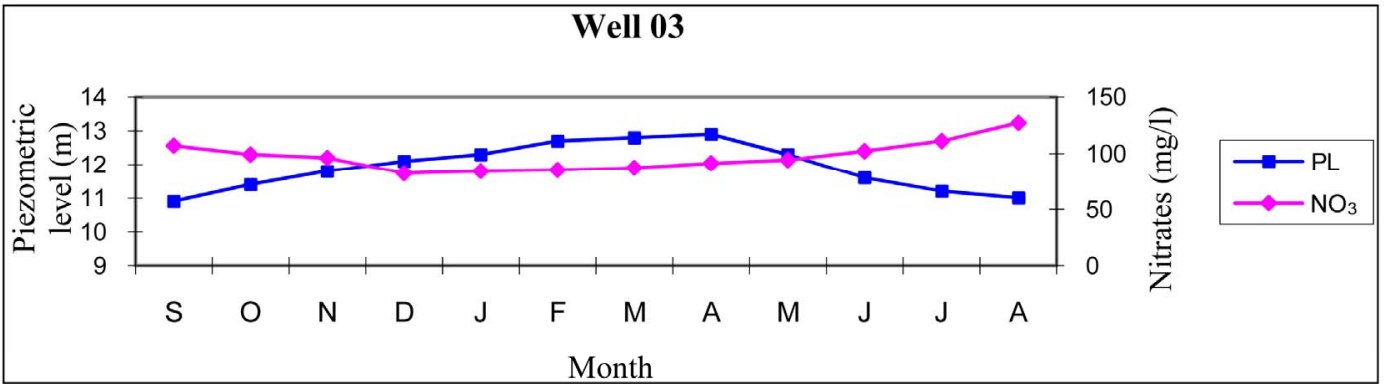

(d)

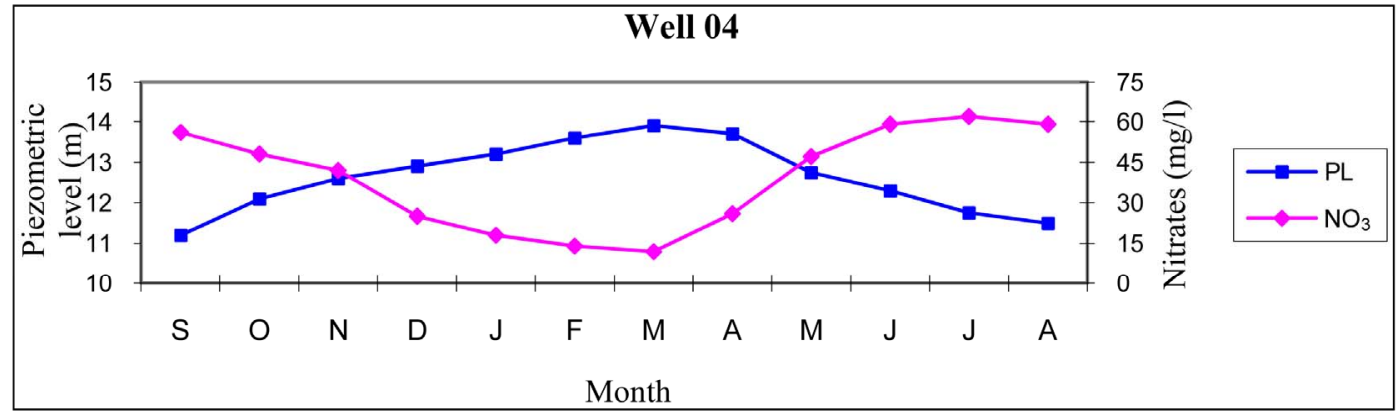

(e)

Figure 5. Evolution of nitrate with piezometric fluctuations (period 2009/2012). 


\section{Conclusion}

The nitric pollution of groundwater in the valley of the wadi Djendjen is of agricultural origin. The excessive use of fertilizers in the perimeters of vegetable gardening associated with important amounts of irrigation involves in-depth nitrogen excess and constitutes the principal factor in the deterioration of groundwater quality. At certain points of water, nitric pollution exceeds $100 \mathrm{mg} / \mathrm{l}$. Fortunately, it is confined to those areas where the groundwater is covered with excessively fertilized and irrigated cultures. The low nitrate levels recorded in protected areas and in water wadi support this conclusion. This finding, although not very alarming, calls however on the fact that the groundwater remains under the threat of a generalized nitrate pollution, if the supply of fertilizers to cultures is not regulated and strictly controlled. It is therefore, without delay, to adopt an action plan aimed at raising awareness among farmers about the dangers of nitrate pollution of groundwater. Well adapted farming practices and rational fertilization, have to be implemented to meet the requirements of good returns within the state of the environment.

\section{REFERENCES}

[1] F. Lasserre, M. Razack and O. Banton, “A GIS-Linked Model for the Assessment of Nitrate Contamination in Groundwater,” Journal of Hydrology, Vol. 224, No. 3-4, 1999, pp. 81-90. http://dx.doi.org/10.1016/S0022-1694(99)00130-4

[2] M. N. Almasri, "Modeling Nitrate Contamination of Groundwater in Agricultural Watersheds," Journal of Hydrology, Vol. 343, No. 3-4, 2007, pp. 211-229. http://dx.doi.org/10.1016/j.jhydrol.2007.06.016

[3] M. J. Shaffer, B. K. Wylie and M. D. Hall, "Identification and Mitigation of Nitrate Leaching Hot Spots Using
NLEAP-GIS technology," Journal of Contaminant Hydrology, Vol. 20, No. 3-4, 1995, pp. 253-263.

http://dx.doi.org/10.1016/0169-7722(95)00072-0

[4] K. L. Addy, A. J. Gold, P. M. Groffman and P. A. Jacinthe, "Groundwater Nitrate Removal in Subsoil of Forested and Mowed Riparian Buffer Zones,” Journal of Environmental Quality, Vol. 28, No. 3, 1999, pp. 692-970. http://dx.doi.org/10.2134/jeq1999.0047242500280003002 $\underline{9 x}$

[5] B. A. Engel, K. C. S. Navulur, B. S. Cooper and L. Hahn, "Estimating Groundwater Vulnerability to Non Point Source Pollution from Nitrates and Pesticides on a Regional Scale," The International Association of Hydrological Sciences, Vol. 235, No. 1, 1996, pp. 521-526.

[6] E. El Tabach, "Study of the Impact of Accidental Pollution and Agricultural Pollution of Groundwater Resources,” Ph.D. Thesis, University of Science and Technology of Lille, Lille, 2005, 240 p.

[7] B. Maticic, "The Impact of Agriculture on Ground Water Quality in Slovenia: Standards and Strategy” Agricultural Water Management, Vol. 40, No. 2-3, 1999, pp. 235-247. http://dx.doi.org/10.1016/S0378-3774(98)00124-3

[8] J. K. Bohlke, "Groundwater Recharge and Agricultural Contamination,” Hydrogeology Journal, Vol. 10, No. 1, 2002, pp. 153-179. http://dx.doi.org/10.1007/s10040-001-0183-3

[9] T. H. Debieche, J. Mania and J. Mudry, "Impact of Agriculture and Land on the Evolution of Nitrates in the Plain of Seybouse (North-East Algeria)," Symposium of Gruttee, Limoges, 2001, pp. 135-144.

[10] A. Boufekane and O. Saighi, "Use of Gis to Characterize the Vulnerability to Pollution-Application to the Alluvial Aquifer of the wadi Nil (Jijel, Northeast Algeria)," International Network Environmental Management Conflicts, Vol. 1, No. 1, 2010, pp. 267-274. 